\title{
Teachers As Learners: Implications Of Adult Education For Professional Development
}

Amy Beavers, University of Tennessee, USA

\begin{abstract}
Effective communication with teachers is a critical element of any successful professional development. Teachers are the foundational component of any educational system. It is vital that adequate attention is focused on appropriate and effective training of these teachers. Ideally, professional development offers a means of collaborative support and training to collectively conquer challenges facing teachers both in and out of the classroom. The need for continued professional development is widely accepted. Certainly, programs based on high-quality and meaningful teacher development can affect teachers' skills and attitudes in the classroom, further increasing the quality of education the students receive. There are numerous resources and studies detailing the components of effective professional development; however, these models can be quite extensive and potentially overwhelming to an administrator who already has enough tasks to occupy their time. By incorporating a few basic principles established within the field of adult education, teacher professional development can dramatically increase its effectiveness. This paper outlines very briefly some of these concepts and offers simple and applicable suggestions for teacher professional development programs such as: the characteristics of adult learners, self-directed learning, transformative learning and critical reflection.
\end{abstract}

Keywords: Teacher Education, Adult Education, Teacher Professional Development, Self-Directed Learning, Transformative Learning, Adult Learners

\section{INTRODUCTION}

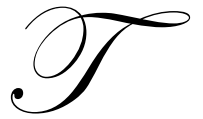

eachers are the foundational component of any educational system. It is vital that adequate attention is focused on appropriate and effective training of these teachers. Teachers are required not only to be experts in their content area, but are also expected to be fluent in child psychology, skilled in communication, execute brilliant classroom management strategies, and navigate the unrelenting gauntlet of educational politics. They must also be familiar and comply with ever-changing federal and state mandates regarding educational standards. Additionally, they are required to attend mandatory teacher professional development (TPD), among other tasks, to ensure their "highly qualified" teacher status that often provides job security. It is an overwhelming undertaking even for the most skilled teacher.

Ideally, professional development offers a means of collaborative support and training to collectively conquer these challenges. The need for continued professional development is widely accepted. For "growth and improvement of any educational institution, teacher professional development becomes a milestone in teachers' continuum of life-long learning and career progression" (Hien, 2008). Most teachers would acknowledge the need for continued training on new technologies, updated educational standards, and relevant classroom strategies. Certainly, TPD based on "high-quality, meaningful and effective teacher enhancement" can affect teachers' skills and attitudes in the classroom, further increasing the quality of education the students receive (Hien, 2008). Unfortunately, as these courses are mandated and become institutionalized, the practical focus turns to credit counting rather than on the actual learning taking place (Confessore \& Confessore, 1994). This required continued 
education can create an atmosphere of resentment towards the directors of the program and the courses themselves (Hiemstra \& Brockett, 1994).

Teachers often are disappointed with the presenter style and format of the lesson, rather than the ideals of staff development. Unfortunately, valuable information is overlooked or unheard due to poor teaching strategies executed by the presenter and insufficient planning by the administration that fails to include the body of teachers in the decision process. Brookfield cites the "disjunction of learning and teaching styles" and "apparent irrelevance of the learning activity" as two reasons that can attribute to resistance to learning (Brookfield, 1990, pp. 151-152). Certainly, having an effective professional development program is a goal of any organization. There are numerous resources and studies detailing the components of effective professional development; however, these models can be quite extensive and potentially overwhelming to an administrator who already has enough other tasks to occupy their time. By incorporating a few basic principles established within the field of adult education, teacher professional development can dramatically increase its effectiveness.

This article outlines very briefly some of these concepts and offers simple and applicable suggestions for teacher professional development programs such as: the characteristics of adult learners, self-directed learning, transformative learning and critical reflection.

\section{CHARACTERISTICS OF ADULT LEARNERS}

Teachers in staff development are often viewed as the "class" or "students" as the presenter adopts the role of the "teacher" or "instructor." Usually, good practices are followed that would be considered appropriate in most primary and secondary classrooms. There are handouts, lectures, group activities, and question sessions. One component, however, is often overlooked: adults learn differently from children. The same practices that work in a traditional educational setting do not always work for a group of adults, especially a group of well educated, independent teachers. Adult educators should strive to be viewed not as the "instructor," but rather work to serve as a "facilitator" (Brockett, personal communication, Fall 2008).

There are many descriptions of the adult learner. Most noted is Malcolm Knowles's description of andragogy. He emphasizes that adults come with a variety of experiences that are crucial to their learning; through those experiences, they come with predefined ideas for what they need to learn (Merriam \& Brockett, 2007). Merriam summarizes Knowles's five assumptions of the adult learner:

as someone who (1) has an independent self-concept and who can direct his or her own learning, (2) has accumulated a reservoir of life experiences that is a rich resource for learning, (3) has learning needs closely related to changing social roles, (4) is problem-centered and interested in immediate application of knowledge, and (5) is motivated to learn by internal rather than external factors (2001).

While modeling current "best practices in teaching" is certainly a valid strategy for teaching teachers, there are clear differences in the best pedagogical practice and andragogical strategies. By being aware of these attributes of the adult learner, it is easier to see how traditional methods of teaching children or adolescents might not be best suited for a group of teachers.

In addition to the general characteristics of adult learners, good teachers have several distinct attributes that define who they are, how they tackle the challenges presented to them, and how they approach learning. Categorically, teachers are problem solvers: questioning, challenging, and adapting to actively meet the needs of their students. Teachers develop a broader awareness for educational opportunities outside of their classroom to consider the educational community as a whole. Additionally, good teachers value the respect of their colleagues, utilizing those supports and resources (Collinson \& Sherrill, 1997). "Every teacher... needs to feel like they are growing, needs to feel the excitement of new possibilities" (Riley \& Roach, 2006). 


\section{Implications for Professional Development}

In professional development, teachers' experiences within the classroom must be respected and utilized, and their practical knowledge cannot be ignored (Trotter, 2006). Schon (as cited in Confessore, 1994) describes this as a "knowing-in-practice." In a study conducted by Sharon Oji looking at adult learning as it applies to TPD, she found that teachers want to problem-solve with their colleagues and learn things that are applicable to practices in their classrooms. "Through these interactive situations, adults were able to reflect, grow, and adapt throughout their teaching careers" (as cited in Trotter, 2006, p. 12). The experiential knowledge and insight that comes from teachers of all experience levels can prove to be exceptionally beneficial and educational for TPD. Ralph Brockett identifies that "most successful adult learning takes place in a collaborative setting" (2008). Providing an environment that allows for these teachers, who share similar experiences, to brainstorm and problem solve not only creates solutions, but it also builds a community atmosphere of trust and appreciation. The peer learning can continue after the professional development activities are over.

Additionally, the purpose and benefit for a specific TPD should be made clear and concrete. Because of the internal motivation for learning and resistance attributed to irrelevant topics (Brookfield, 1990), teachers need to see the application for their practice in order to be active participants. Vague, philosophical jargon and external incentives are not likely to be effective as motivators for teacher participation. However, it should be mentioned that external motivators such as professional status and social outlets have been shown in some to increase initial interest. Because TPD is usually required and not all teachers can be inspired to learn each time, external incentives could be beneficial (Livneh \& Livneh, 1999).

\section{SELF-DIRECTED LEARNING}

"Simpson noted two distinguishing traits in adult learners: the autonomy of direction of learning and the use of experience as a resource" (Trotter, 2006, p. 11). Adult learners tend to resist learning that is in conflict with the direction they believe their learning should go. "The key to working successfully with adults is participation. Ideally, the learner should be an active participant in a learning activity that is a cooperative venture" (Conti, 1989, p. 5). Therefore, it is important to understand the ideas of Self-Directed Learning (SDL) and how those concepts apply to teachers as learners. While there are many contemporary sources that discuss the components and definitions of SDL, the ideas are not new and have been illustrated by the founding father of education, Socrates. Socrates illustrates concisely the concepts of Self-Directed Learning in his discussion with Meno by allowing him to determine the topic of interest (The Great Dialogues of Plato). Learning that takes place from personal inquiry is often the most effective and lasting.

In the modern research of adult education, it was Alan Tough who furthered the foundational work of Houle and Knowles and conducted the first studies specifically focused on self-directed learning activities, concluding that learning "occurs as part of adults' everyday life" (Merriam, 2001, p. 8). The work of Tough in 1966 drew attention and interest to the concept (Percy, Burton, \& Withnall, 1994). It inspired a large amount of research in the field resulting in a variety of models of SDL. Stemming from the basic idea that adult learners "should have their adulthood respected and not be treated by their teachers as dependent" (Percy, Burton, \& Withnall, 1994, p. 11), the various philosophical goals of SDL have emerged. Merriam identifies three goals: (a) "the development of the learner's capacity to be self-directed" (b) the "fostering of transformational learning" as discussed by Brookfield and (c) "the promotion of... social action" seen as the foundation for schools like Highlander (Merriam, 2001, p. 9). It should be noted that personal characteristics and levels of readiness for SDL influence the applicability of SDL for a large group.

\section{Implications for Professional Development}

A problem that arises when applying Self-Directed Learning principles to TPD is that, by definition, organized and structured self-directed learning might be a contradiction (Penland, 1979). As Hiemstra and Brockett (1994) explain, self-direction is not an "all-or-nothing" concept. It can be effectively implemented in a variety of settings, including professional development, by allowing teachers to be involved with planning their own professional development. Trotter (2006) suggests that "allowing the teachers to determine what direction their 
professional development will take will greatly increase the success of the teachers in their journey to be lifelong learners" (p. 11).

\section{TRANSFORMATIVE LEARNING}

As previously discussed, Knowles emphasizes the importance of experience to the learning process of adults. Simply having the experience is not what makes adult learners categorically difference from other learners. It is the way that experience changes and influences them to further learn and grow (Brockett, 2008). Jack Mezirow conducted a study in 1975 observing the process change of women re-entering college were forced to evaluate previous assumptions and patterns and adapt new behaviors and boundaries in order to function successfully. Mezirow (2000) defines this process as transformative learning and explains that it takes place when experiences and situations require us to "open up our frame of reference, discard habit of mind, see alternatives, and thereby act differently in the world" as cited in (Cranton \& King, Transformative Learning as a Professional Goal, 2003).

Patricia Cranton (1994) has applied the theories of transformational learning to the practice of teaching. She explains that teachers should be led to critically examine their practice: that by increasing a sense of understanding of self and others, teachers are able to engage in transformative learning that is so critical to successful teaching (Cranton, 1996; Cranton \& King, 2003). Brookfield believes that critically reflective teaching is a continual process in which teachers question and reflect on what they do, why they do it, what works, and why they believe it is important (Brookfield, 1990). Brockett (2008) wrote, "The ultimate purpose of adult education is to help learners think for themselves."

\section{Implications for Professional Development}

"Meaningful professional development must...involve educators as whole persons- their values, beliefs, and assumptions about teaching" (Cranton \& King, 2003, p. 33). Creating an environment where educators are comfortable with active involvement and critical reflection is often complex and requires teachers to be willing to take risks (King, 2004). An atmosphere that encourages self-expression and exploration is essential. When "individuality, uniqueness, [and] difference" are valued, there is freedom to explore new ideas (Lindeman, 1961, p. 36). Effective TPD must include personal, critical reflection, active participation, and willingness to share and challenge other perspectives. Most importantly, a supportive, accepting environment must be in place (King, 2004).

King (2004) also points out the challenge of this critical evaluation of teachers' own ideas. She explains the difficulty of teachers to question their prior understanding and belief, emphasizing the need for acceptance and support from others as they challenge themselves to become better, more effective teachers. Potentially, pain and loneliness are felt due to the risk of new ideas and loss of comfortable patterns (Zellermayer \& Margolin, 2005). The best teachers are continually experimenting with new methods and ideas to create the best learning environment for their students. Professional development must strive to help teachers learn to talk about their practices and experiences. It must enable teachers to share their knowledge of experience with one another. Then, these practical ideas must be effectively generalized into applicable concepts for other teachers (Riley \& Roach, 2006).

\section{CONCLUSION}

Effectively educating teachers requires actively viewing adults as unique learners. There are numerous, extensive theories for the best professional development. I would argue, however, that most school systems, which are daily facing many other challenges, are reluctant to implement such complex strategies. Contrastingly, incorporating adult education principles into the programs they already have in place may be accomplished with relative ease by following these guidelines:

- $\quad$ Allow teachers to provide input about topics of professional development

- Utilize teachers' variety of experiences as learning opportunities

- $\quad$ Keep topics practical and applicable rather than theoretical and philosophical

- $\quad$ Facilitate dialogue among peers geared towards problem-solving

- $\quad$ Provide options and alternatives to support different learning styles 
- $\quad$ Encourage teachers to facilitate the learning activities rather than having them organized by administrators

- $\quad$ Create a system-wide atmosphere that appreciates diversity, openness, and critique

- $\quad$ Support alternate theories and reflections for everything from teaching strategies to board policy

Teacher Professional Development must recognize that teachers have different needs and appreciate that practice is unique for each teacher with each class. If directors of professional development are to effectively educate their teachers, they must respect their individuality and allow for self-direction. They must welcome diversity and healthy disagreement among their faculties. Ultimately, educators, as Houle urges, "should involve learners in as many aspects of their education as possible and in the creation of a climate in which they can most fruitfully learn" (Merriam, 2001, p. 6).

\section{AUTHOR INFORMATION}

Amy S. Beavers is a Ph.D. student in Educational Psychology and Research at the University of Tennessee, Knoxville. She is specializing in Evaluation, Statistics and Measurement.

\section{REFERENCES}

1. Brockett, R. G. (2008). Ten Important Ideas About Adult Learning. Unpublished document, University of Tennessee.

2. $\quad$ Brookfield, S. D. (1990). The Skillful Teacher. San Francisco: Jossey-Bass.

3. Collinson, V., \& Sherrill, J. (1997). Changing Contexts for Changing Roles: Teachers as Learners and Leaders. Teaching Education, 8, 55-63.

4. Confessore, G. J., \& Confessore, S. J. (1994). Adopting Self-Directed Learning in Continuing Professional Education: Physicians and Architects. In R. Hiemstra, \& R. G. Brockett, Overcoming Resistance to SelfDirection in Adult Learning (pp. 31-38). San Francisco: Jossey-Bass.

5. Conti, G. J. (1989). Assessing Teaching Style in Continuing Education. In E. Hayes, Effective Teaching Styles (pp. 3-16). San Francisco: Jossey-Bass.

6. Cranton, P. (1996). Professional Development as Transformational Learning. San Francisco : Jossey-Bass.

7. Cranton, P. (1994). Understanding and Promoting Transformative Learning: A Guide for Educators of Adults. San Francisco: Jossey-Bass.

8. Cranton, P., \& King, K. (2003). Transformative Learning as a Professional Goal. New Directions for Adult and Continuing Education, 98, 31-37.

9. Hiemstra, R., \& Brockett, R. G. (1994). Resistance to Self-Direction in Learning Can Be Overcome. In R. Hiemstra, \& R. G. Brockett, Overcoming Resistance to Self-Direction in Adult Learning (pp. 89-92). San Francisco: Jossey-Bass.

10. Hien, T. (2008). Towards an Effective Teachers Professional Development in DFLSP. Retrieved on November 29, 2008, from http://vocw.edu/content/m11296/latest/

11. King, K. P. (2004). Both Sides Now: Examining Transformative Learning and Professional Development of Educators. Innovative Higher Education, 29(2), 155-174.

12. Lindeman, E. (1961). The Meaning of Adult Education. New York: Harvest House.

13. Livneh, C., \& Livneh, H. (1999). Continuing Professional Education Among Educators: Predictors of Participation in Learning Activities. Adult Education Quarterly, 49(2), 91-106.

14. Merriam, S. B. (2001). Andragogy and Self-Directed Learning: Pillars of Adult Learning Theory. New Directions for Adult and Continuing Education, 89, 3-12.

15. Merriam, S. B., \& Brockett, R. G. (2007). The Profession and Practice of Adult Education. San Francisco: Jossey-Bass.

16. Merriam, S., \& Caffarella, R. (1999). Learning in Adulthood. San Francisco: Jossey-Bass.

17. Mezirow, J.; and Associates. (2000). Learning as Transformation. San Francisco: Jossey-Bass.

18. Penland, P. (1979). Self-Initiated Learning. Adult Education Quarterly, 29(3), 170-179.

19. Percy, K., Burton, D., \& Withnall, A. (1994). Self-Directed Learning among Adults: the Challenge for Continuing Educators. Lancaster: Association of Lifelong Learning.

20. Plato (1956). The Great Dialogues of Plato. (Rouse, W.) New York: New Amerian Library. 
21. Riley, D. A., \& Roach, M. A. (2006). Helping Teachers Grow: Toward Theory and Practice of an 'Emergent Curriculum' Model of Staff Development. Early Childhood Education, 33(5), 363-370.

22. Schon, D. (1987). Educating the Reflective Practitioner: Toward a New Design for Teaching and Learning in the Professions. San Francisco: Jossey-Bass.

23. Trotter, Y. D. (2006). Adult Learning Theories: Impacting Professional Development Programs. Delta Kappa Gamma Bulletin, 72(2), 8-13.

24. Zellermayer, M., \& Margolin, I. (2005). Teacher Educators' Professional Learning Described Through the Lens of Complexity Theory. Teacher College Record, 107(6), 1275-1304.

\section{$\underline{\text { NOTES }}$}

